\author{
Marquette University \\ e-Publications@Marquette
}

School of Dentistry Faculty Research and

Publications

Dentistry, School of

$3-2014$

\title{
Fostering Dental Faculty Collaboration with an Evidence-Based Decision Making Model Designed for Curricular Change
}

Gary L. Stafford

Marquette University, gary.stafford@marquette.edu

Follow this and additional works at: https://epublications.marquette.edu/dentistry_fac

Part of the Dentistry Commons

\section{Recommended Citation}

Stafford, Gary L., "Fostering Dental Faculty Collaboration with an Evidence-Based Decision Making Model Designed for Curricular Change" (2014). School of Dentistry Faculty Research and Publications. 47.

https://epublications.marquette.edu/dentistry_fac/47 


\title{
Fostering Dental Faculty Collaboration with an Evidence-Based Decision Making Model Designed for Curricular Change
}

\begin{abstract}
Gary L. Stafford, D.M.D.
Abstract: This article introduces an innovative decision making model for adapting evidence-based practice to the specific needs of a department in a dental school. The design encourages suggestions for curricular change directly from the faculty members, while providing a mechanism that allows them to actively participate in the process through the use of evidence-based principles and practice. The nucleus of this model is an Advisory Council comprised of nine full-time departmental faculty members who, when charged, act as independent task force leaders who recruit other faculty members and lead small teams that investigate suggestions for curricular change. Following an accelerated investigative process, recommendations to the Advisory Council are made; if approved, these changes are integrated into the curriculum. The incorporation of an interdisciplinary Advisory Council of key departmental faculty members structured to investigate questions or concerns posed by students, administrators, or other faculty members through the use of evidence-based methodologies has proved to be a successful management tool. Well received by the participants, this model has the potential to further develop and calibrate the school's faculty, increase the timeliness of the decision making process, and lessen the time required to incorporate a proposed change into the curriculum.
\end{abstract}

Dr. Stafford is Chair, Department of General Dental Sciences, Marquette University School of Dentistry. Direct correspondence and requests for reprints to Dr. Gary L. Stafford, Department of General Dental Sciences, Marquette University School of Dentistry, 1801 W. Wisconsin Ave., Room 336C, Milwaukee, WI 53201-1881; 414-288-5409; gary.stafford@mu.edu.

Keywords: dental education, dental faculty, curriculum, dental school curriculum, evidence-based dentistry, evidence-based practice

Submitted for publication 11/30/12; accepted 4/19/13

$\mathrm{C}$ ognitively, decision making is a very complicated process fraught with many personal biases. ${ }^{1}$ Every instruction we give, every course of action we set, every result we desire starts with a decision, but unfortunately this decision making process is often based upon what we think we know. ${ }^{2}$ It is common knowledge that many practicing clinicians have closely held professional opinions or beliefs regarding the delivery of oral health care that could have a negative impact on their treatment outcomes. The evidence-based dentistry (EBD) model was specifically designed for the clinician to more easily navigate the wealth of available literature in order to circumvent the continuation of practice based more on this professional opinion rather than on scientific fact. ${ }^{3}$ Chairs of academic departments can also suffer from making decisions based on these same types of closely held opinions or beliefs. However, the consequences of using a preconceived notion as a basis for decision making will have an exponentially greater negative effect when one is responsible for educating the next generation of dentists. Disturbingly, the very individuals empowered with the great responsibility of making these decisions are more likely to bring their previously formed beliefs or hypotheses into the decision making situation with a tendency to overlook information or evidence that would counter their preconception. ${ }^{4}$ In addition, it is not only one's personal biases that can be problematic when making important departmental decisions. If faculty members' work requires them to make difficult decisions all day long, at some point they will look to avoid or postpone decisions. They will look for the safest and easiest option, which is often to stick with the status quo. ${ }^{5}$ In the continuous effort to stay abreast of best practices, best evidence, and the ever-changing world of clinical materials and techniques required to maintain curricular currency with professional advances, preserving the status quo is oftentimes the least acceptable alternative when an educational institution is contemplating curricular change.

The curriculum of any academic dental institution is not, and should not be, a static entity. As such, it must continually be reviewed and modified to meet the changing demands of the profession. Department chairs, acting as agents of change in their respective institutions, should share in this desire to seek out opportunities to provide innovative strategies for improving curricular content, while helping to foster 
an academic environment that values intellectual curiosity by both the students and the faculty members who train them.

A department chairperson functions in part to oversee the content associated with the courses within his or her department, but a chairperson is not merely a steward of the curriculum designed by the Curriculum Committee. A department chair must also be actively engaged in ensuring that curricular content remains relevant and that it supports the goals of the department. Ongoing periodic reviews should be initiated that can lead to the changing of courses, updating of course content, selecting different clinic materials, or modifying clinical techniques. Department chairs in a fast-changing world must be knowledgeable about directions and tendencies; they must be avid readers and observers of new professional developments; and they must be persuasive enough to engage their faculty members in this pursuit. Similarly, in order to attain a degree of success in their position, they must lead by building consensus with faculty members who need to be involved in changes in the department. ${ }^{6}$ Building consensus is often problematic due to the fact that resistance to change is a natural human reaction. ${ }^{7}$ For a department chair or a leader in any capacity, overcoming these natural tendencies is paramount in achieving the goal of successful implementation of curricular change. ${ }^{8}$ Involving the faculty in the decision making process may help to create a sense of ownership that should help to overcome some of the natural resistance to change and allow for a higher degree of acceptance and ultimately a higher degree of success.

Just as it has become increasingly difficult for a practicing dentist to stay current with changes related to oral health care, so it is for the chairperson who is contemplating curricular revisions in his or her department. A 2009 survey of dental school curricula analyzed what triggered curricular change in dental institutions. With 86 percent of North American dental schools (fifty U.S. and five Canadian) responding, 80 percent indicated that they relied on educational best practices reported in the literature as either highly important or important catalysts for change. ${ }^{9}$ Similarly, 77 percent of the same schools responded that it was new scientific evidence they wished to incorporate into the curriculum that motivated them to make a change. The results of this survey make it clear that there is a need for the same systematic approach to the discovery of best external evidence for either educational practices or scientific evidence as there is for dentists in clinical practice.
The purpose of this article is to describe an innovative organizational model of how Marquette University School of Dentistry adapted evidencebased practice (EBP) to its specific needs - an evolution in the use of evidence-based methodologies that was predicted in $1996 .{ }^{10}$ It will illustrate how an organization, department, or program can institute a relatively simple structural design that will help to create consensus for, and increase faculty acceptance of, departmental decisions. This evidence-based decision making (EBDM) model alternatively acts as a management tool, a faculty consensus builder, a strategic faculty development method, and a way to facilitate more rapid changes in the department. The combined use of EBDM by key departmental faculty members who lead small task-oriented teams has led to a deeper understanding and appreciation of the advantages of EBD, with the added advantage of educating and calibrating the faculty in EBP. The use of EBDM at the highest level of departmental administration has also helped to reinforce what we teach our predoctoral students by showing that we follow the principles of EBP in seeking the best external evidence when making decisions that have an impact on the curriculum. Ultimately, however, this model's greatest strength lies in its ability to foster collaboration among those individuals who participate in the investigative process.

\section{Background}

The adoption of a new curricular model in 2000 following Dean William K. Lobb's 1999 Report of Curricular Revision highlighted the importance of EBD as a key component of contemporary dental education. The concept and practice of EBD were first introduced to the D1 (first-year) dental students as part of this new curriculum in 2002 and, to this day, remain an integral part of the dental rounds education model in which we link the basic sciences to clinical care. Building on the curriculum established in 2002 and wishing to further enhance the teaching and practice of EBD, I attended a workshop on evidencebased methodologies at the University of Oxford, UK, in May 2007 (courtesy of a federal grant) in order to become more proficient in the practice of EBD. Utilizing the skills and knowledge gained by this experience, we began work in earnest to develop a model that would integrate EBD into the curriculum in a way in which it would be taught and used in an authentic clinical application. 
Time and location in the curriculum had been established, and a model was close to completion when during the 2008 annual meeting of the American Dental Education Association's Commission on Change and Innovation in Dental Education (ADEA CCI) liaisons, Marquette's liaisons heard John D. Rugh, Ph.D., from the University of Texas Health Science Center at San Antonio Dental School (UTHSCSA), speak on "Assessment of Student Search and Critical Appraisal Skills." This presentation complemented the discoveries I had made at the University of Oxford and provided a tested framework for implementation of EBD into our curriculum. Using the UTHSCSA model as a reference, our existing model was modified into a more robust series of EBD lectures and projects, which, beginning with the fall semester of 2008, were integrated into the existing D3 (third-year) curriculum. Designed to work in concert with didactic instruction, the tasks assigned to students were to formulate a clinical question that directly related to one of their patients and then convert the clinical question into a PICO format. This format, which identifies the patient, problem, or population $(\mathrm{P})$, the intervention (I), the comparison $(\mathrm{C})$, and the measurable outcomes $(\mathrm{O})$, helps focus the question on the single most important issue and outcome. The students conducted a search for the best available evidence and were then required to assess the quality of the studies they selected. At the end of the fall semester, the students defended their findings in presentations to their peers in which they outlined their path of discovery in uncovering the scientific support for their clinical question. The students gave such positive reviews of this portion of the course that a decision was made to maintain it as part of the curriculum, to further enhance the model, and to begin calibrating and/or further educating the full-time faculty in EBP.

Due to his influence on the Marquette liaisons in attendance at the 2008 ADEA CCI liaisons' meeting, in December 2009, Dr. Rugh was invited to speak at the school's Faculty Development Day on "Strategies to Deal with the Information Explosion in Education and Practice" in an attempt to further the full-time faculty members' exposure to EBDM. This presentation provided a solid overview of EBDM and not only gave our full-time faculty members an overview of methodologies and student assessment, but also illustrated how best to categorize and format the results via the use of the Critically Appraised Topics (CATs) template. ${ }^{11,12}$ Over the next two years, this "bottom-up" approach of integrating EBD into the curriculum and ultimately into clinical practice continued to be a highly successful educational experience. Although the students were exhibiting greater skills and comfort in EBP, it became apparent that the part-time and many of the full-time faculty members were not at the same level of proficiency as some other full-time faculty members. Analysis of the problem suggested that this shortcoming was due to a lack of involvement by the less proficient faculty members, stemming from their not fully understanding the mechanics of EBD. This simple lack of understanding led to negative personal biases, reluctance to participate with the students, and underappreciation of the value of EBDM. This analysis also revealed an opportunity to address these faculty shortcomings as well as to create a mechanism that would improve the department's decision making ability when managing curricular change.

\section{Methods}

Although its philosophical origins go back centuries, evidence-based practice is a relatively young discipline. It has been predicted that as predoctoral, postdoctoral, and continuing medical education programs adopt its approach and adapt it to their specific needs, continued evolution in its use will be seen. ${ }^{10}$ One such evolutionary advancement has been the integration of EBDM in handling curricular issues in the Department of General Dental Sciences at the Marquette University School of Dentistry.

EBDM has been defined as the formalized process of using the skills of identifying, searching for, and interpreting the results of the best scientific evidence, which is considered in conjunction with the clinician's experience and judgment, the patient's preferences and values, and the clinical/patient circumstances when making patient care decisions. ${ }^{13}$ This systematic process of critically appraising the best external evidence is not only an integral component of EBP, but these fundamental principles can also be applied in making decisions as they relate to changes in an academic department's curriculum, both didactically and clinically.

In an effort to educate and involve the faculty, a three-step, "top-down" approach was designed to complement the successful "bottom-up" student education approach. Unveiled at the department's annual meeting in January 2011, the first step in this approach was a brief overview of why EBD was important, where we currently were in our teaching, 
where we were headed, what the expectations of faculty members were, and how they could participate in the process. The second step was to provide an opportunity for faculty members to further enhance their knowledge and understanding of EBD. A date was selected for a continuing education course, which I presented soon after the department's annual meeting. This course, titled "Fundamentals of Evidence-Based Decision Making," provided foundational knowledge related to EBD to the department's faculty. To encourage attendance, both full- and part-time faculty members received complimentary tuition and credit courtesy of our school's Office of Continuing Education.

The third and final step in this "top-down" approach was much broader in scope and entailed the creation of a new organizational body. This body was designed to act as the major decision making group for the department, base its decisions on the best available evidence, use methods that mirrored those of the students, engage both full- and part-time faculty members, and possess the ability to affect rapid change. The name chosen for this new organizational group was the Department of General Dental Sciences Advisory Council (GDS AC). The department chair serves as the de facto leader of the GDS AC, which is comprised of nine full-time faculty members representing all of the department's predoctoral programs, graduate programs, and disciplines (Table 1). Each member, when charged, organizes and leads a task force until the assigned task is complete.

The GDS AC meets on a monthly basis to assign new tasks, review the progress of previously assigned tasks, discuss and vote on specific task force recommendations, and create a departmentwide action plan for implementation of any approved recommendations. These meetings, held prior to the start of the clinic day, run approximately one hour

\section{Table 1. Programs and disciplines represented on the Department of General Dental Sciences Advisory Council}

Advisory Council
Biomaterials
Fixed Prosthodontics
Implants
Oral Medicine and Radiology/TMD
Quality Control/Quality Assurance
Removable Prosthodontics
Restorative
Treatment Planning

in length. In an effort to provide transparency for these key departmental decisions, monthly reports are made available to all full- and part-time faculty members after each meeting.

Curricular suggestions or specific clinical questions are encouraged, may be posed by anyone at the School of Dentistry, whether faculty, staff, or student, and are brought directly to the department chair's attention (Figure 1). Ideas or questions may be submitted anonymously, verbally, or in written form, and each is taken to the next GDS AC meeting for discussion. If the suggestion is deemed appropriate by vote of the sitting members, a task force team leader is chosen and charged based on the specialty or discipline to which the question most closely relates. The task force team leader (TFTL) is then responsible for selecting task force team members (ideally no more than three) to perform the required research and find the best external evidence necessary to answer the question. In choosing the task force team members, every effort is made to encourage involvement by our part-time faculty members as well as those full- and part-time members from outside of the department. The expectation is for the task force team to meet at least weekly in order to facilitate a timely completion of the assigned task and to be ready to update the GDS AC with its progress or a final recommendation at the next monthly meeting.

Once a task is complete, a slightly modified version of the student's CATs template is prepared and brought to the GDS AC's monthly meeting. The TFTL delivers a summary report, and should the recommended change relate to dental biomaterials or a specific clinical procedure, the TFTL also outlines the specifics of the clinic protocol or technique that would be integrated into the curriculum. Following a discussion addressing any questions or concerns, a vote on whether or not to implement the task force's recommendation is made, with the department chair retaining the right to overrule any recommendation should he feel it is not in the best interest of the department. Once a recommendation is approved, it falls upon the department chair to create a department-wide strategy for implementation of the approved change. This strategy includes when and where the necessary didactic instruction will occur, timing for faculty education and calibration, and defining a timeline for clinical introduction.

To complete the cycle of investigation and change, should the task relate directly to clinical materials, methods, or techniques, as they often do, an update is made to the students' and faculty members' 


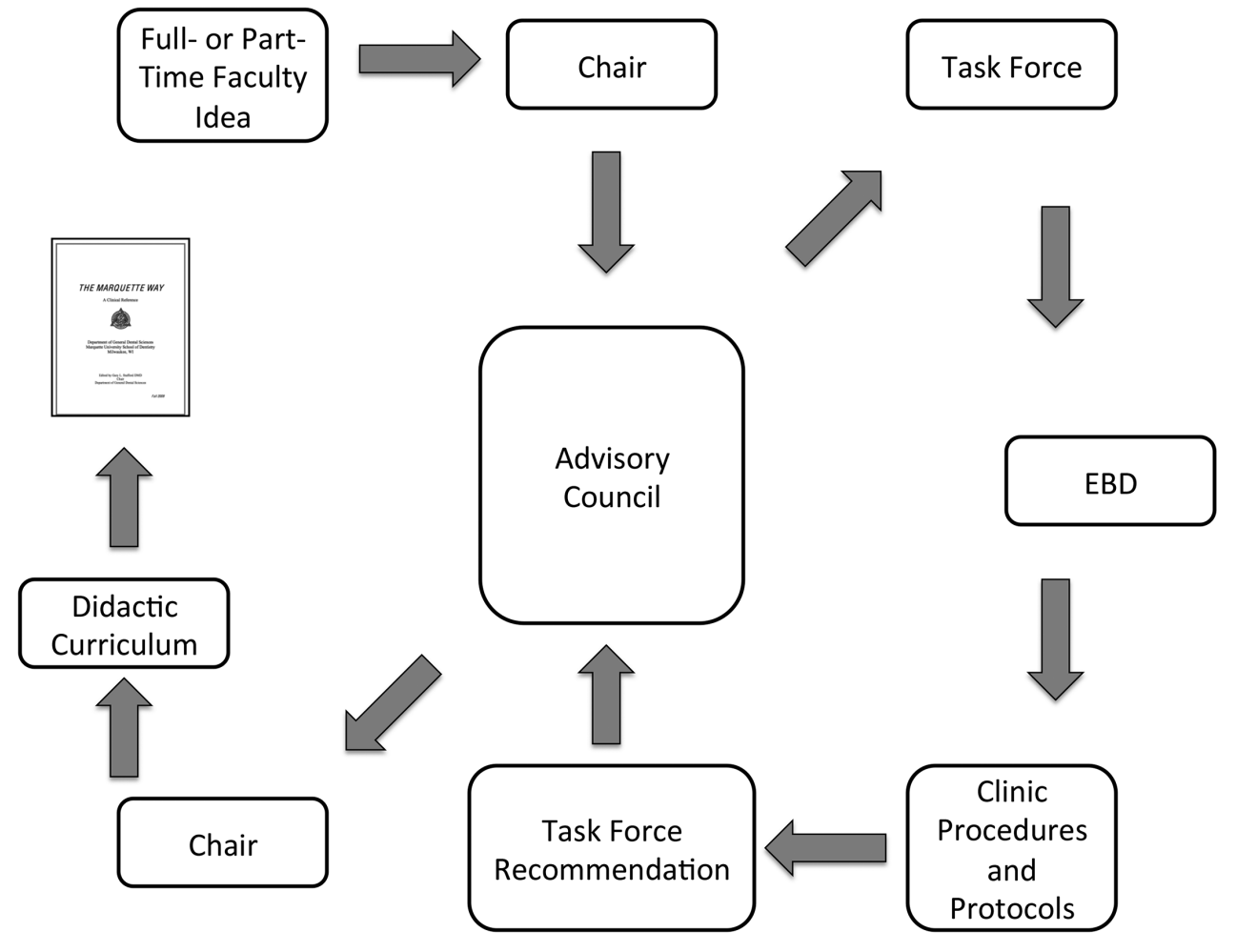

Figure 1. Process by which a curricular idea is introduced, researched, approved, and implemented as policy

primary clinical resource manual, "The Marquette Way." Once this occurs, the change is considered to be the School of Dentistry's standard for that specific clinical procedure. The assessment of an individual Task Force performance in the use of evidence-based methodologies is performed by the department chair using a rubric similar to the one designed for evaluation of the students. This rubric (Table 2) enables the department chair to identify strengths and weaknesses that can be discussed with task force leaders after a summary report and recommendation are made to the GDS AC. Any necessary modifications to the summary report are made prior to its posting on the School of Dentistry's intranet site.

\section{Discussion}

Making departmental curricular decisions demands a systematic approach that seeks out the best available evidence or best educational practices as well as a sound mechanism by which change can be instituted in a timely, structured manner. As a result of the large number of daily decisions a department chair must make and the likelihood that decision fatigue will lead to postponement or avoidance of making any decision at all, it would seem advantageous to delegate the task of seeking out the best available evidence related to the decision at hand to key, hand-selected individuals. Without a defined system, the ability to separate best evidence from opinion is difficult, especially for those of us who have the responsibility of making decisions for an academic department. Fortunately, most department chairs have a depth and breadth of experience that qualifies them to be considered experts in their field. ${ }^{14}$ Unfortunately, due to the cognitive conflicts that can arise due to prior perceptions, one can more easily understand why a department chair, when making any decision, might automatically assume it to be correct due to this vaunted position as an expert.

Academic life appeals to those individuals who enjoy being recognized as experts, who like being professionally challenged, and who appreciate 
working in an environment that affords intellectual stimulation and growth. ${ }^{15}$ This innate intellectual inquisitiveness is a desirable trait of those who wish to seek out the best scientific evidence or the best educational practices when making curricular decisions. However, without a systematic approach in dealing with the volume of scientific and educational information available, the decision maker will face an overwhelming challenge when trying to parse through all of the data at his or her disposal. The enormity of this task is much too time-consuming for a single individual to manage, especially when one has multiple areas of responsibility in a variety of disciplines. One thing is certain: department chairs are incredibly busy people. One extensive review of the duties of a department chair by a University of Nebraska research team listed ninety-seven different activities in which a chair has some form of responsibility. ${ }^{16}$ In an effort to consolidate these activities into broader, more encompassing categories, a relatively recent survey of over 800 department chairs revealed four comprehensive roles a department chair plays that are critical to department productivity and faculty survival. These roles, in no particular order, were listed as Faculty Developer, Manager, Leader, and Scholar. ${ }^{17}$ When acting in each of these separate yet interdependent roles, judgments must be made about why we teach, what we teach, and how we teach, with the department chair remaining cognizant of the cost a poor decision has on the students, faculty, and institution as a whole. In essence, the act of making decisions is at the heart of a department chair's job description.

Facilitating change by building consensus among departmental faculty members requires acting primarily in the comprehensive role as Leader of the department. It has been suggested that it may be useful to approach leadership from the point of view of four different perspectives, lenses, or "frameworks": a structural framework, a human resources framework, a political framework, and a symbolic framework. ${ }^{18}$ These frameworks help agents of change conceptualize different approaches in how best to deal with a specific issue, while the strategies for choosing one or more of these frameworks are dictated by circumstances of the situation in which leaders find themselves. Given the desire to develop a "top-down" approach in teaching EBD and expanding the use of EBP, use of the structural lens provided focus for the conceptualization and development of an innovative organizational structure that helped us achieve our departmental goals.

The concept and design for the GDS AC arose from not only recognizing the critical importance and impact that decisions made on behalf of the department could have, but also the desire to engage, motivate, and involve the faculty in EBP and the need to reach these conclusions in a timely manner. Having a clear vision and a sense of purpose that EBDM in a "top-down" approach was the strategy to

Table 2. Summary report rubric

\begin{tabular}{|c|c|c|c|c|}
\hline Unacceptable (1) & Needs Improvement (2) & Acceptable (3) & Above Average (4) & Exceptional (5) \\
\hline $\begin{array}{l}\text { Key information/data } \\
\text { omitted, incomplete } \\
\text { of incorrect. Irrelevant } \\
\text { information detracted } \\
\text { from report. Outcome } \\
\text { measure not achieved. }\end{array}$ & $\begin{array}{l}\text { Some key information } \\
\text { partially complete, } \\
\text { missing, or incorrect. } \\
\text { Some extraneous } \\
\text { information detracts } \\
\text { from report. Outcome }\end{array}$ & $\begin{array}{l}\text { Minor omissions of key } \\
\text { information or irrel- } \\
\text { evant information did } \\
\text { not detract from report. } \\
\text { Outcome measure } \\
\text { basically achieved. }\end{array}$ & $\begin{array}{l}\text { Includes all key impor- } \\
\text { tant information. Extra- } \\
\text { neous information did } \\
\text { not detract from case. } \\
\text { Outcome measure } \\
\text { clearly achieved. }\end{array}$ & $\begin{array}{l}\text { Exceptionally com- } \\
\text { plete with presentation } \\
\text { of key information. No } \\
\text { omissions/extraneous } \\
\text { information. Excellent } \\
\text { outcome measure. }\end{array}$ \\
\hline
\end{tabular}
measure partially achieved.

\begin{tabular}{lllllll}
\multicolumn{1}{c}{ Outcome Measure } & \multicolumn{3}{c}{ Score } & \multicolumn{1}{c}{ Comments } \\
\hline Clinical question is stated clearly in PICO format. & 1 & 2 & 3 & 4 & 5 \\
Literature search is complete/documented. & 1 & 2 & 3 & 4 & 5 \\
Report is clear, organized, comprehensive. & 1 & 2 & 3 & 4 & 5 \\
Summary synthesis statement is clearly presented. & 1 & 2 & 3 & 4 & 5 \\
MESH terminology is clear and focused. & 1 & 2 & 3 & 4 & 5 \\
Evidence is critically appraised for validity and use. & 1 & 2 & 3 & 4 & 5 \\
Overall impression & 1 & 2 & 3 & 4 & 5
\end{tabular}


be employed, the first phase in designing the model was to structure a group that would help to advance this plan. Given the time restraints placed on a department chair as a result of multiple roles, duties, and responsibilities, it becomes readily apparent that any decisions pertaining to the curriculum cannot, and should not, be made unilaterally and that these decisions require significant input from other key departmental faculty members. As such, it was concluded that a collective effort involving departmental leaders would be required in order to have a reasonable expectation of success. Employing a reversed organizational hierarchy, nine experienced full-time faculty members who represented every program, specialty, or discipline within the department were selected for participation.

Having chosen the individual representatives, a decision making style for the GDS AC needed to be selected. The most common decision making style is the Collective-Participative style in which the leader involves the members of the organization and they in turn share information, ideas, and perceptions with the leader. However, the leader alone makes the decision, thereby maintaining total control, and is also solely responsible for the consequences. This is the standard academic committee model that is easily recognizable and one with which virtually every academician is familiar. The major disadvantage of this style is that it is most often a slow, time-intensive process due to the number of people involved in making the decision. The slow and somewhat autocratic nature of this style of decision making was completely contradictory to my vision of faculty engagement and timely decision making.

Successful administration of a department should not be about a singular voice; rather, a department chair should strive to pull people together to get the very best out of them. It seems as though there are as many leadership styles as leaders, but they all appear to be variations of a theme. The HerseyBlanchard Situational Leadership Theory ${ }^{19}$ defines four main leadership styles (Table 3) and states that their specific use should be based upon the level of maturity of those who are being led (Table 4). The group of individuals selected to participate in the GDS AC each had high skills within their specific areas of expertise but lacked confidence in the execution of EBP. As described in the Hersey-Blanchard Situational Leadership Theory, these individuals, who were ready and willing to participate in the task, would be categorized at an M3 level of maturity. When acting in the comprehensive role of Leader for individuals with this level of maturity, the HerseyBlanchard theory suggests that they respond best to a Participating/S3 style of leadership (Table 5). This leadership style, in which the leader fosters relationships, works along with the team, and shares in the decision making responsibilities, meshed perfectly with my vision for the GDS AC.

When applied to managing a planned change, the Bolman and Deal framework approach to leadership can also be a useful tool. ${ }^{18}$ Seeing developments through a structural lens allows a manager to focus on practical implications of change such as developing and implementing a clear division of labor for accomplishing the tasks necessary to move the change process forward, creating appropriate mechanisms for integrating individual, group, and unit efforts, and providing effective and diligent overall management of the change process. ${ }^{20}$ With these practical implications serving as guides, the design of our model entered its second phase: operational design and function.

Bringing faculty members together in such a way as to facilitate, not hinder, the decision making process can be a challenge, and meeting this challenge requires effective management strategies. When acting in the comprehensive role of Manager of the department, the proposed model acts as a management tool that helps to create a structured, collaborative, interdisciplinary working environment along with specific timelines and clear expectations. This allows any faculty member to not only have a voice in questioning what, when, where, why, and how we are currently teaching, but also an opportunity to actively participate in answering his or her own question and discovering new instructional methodologies using a non-threatening, well-defined process.

Intellect and desire are no substitute for action, and there is no better way to get something done in a timely manner than to have a small group of individuals focus on a specific objective with well-defined expectations and deadlines. ${ }^{21}$ The task force concept, as opposed to the more formal, slower moving, traditional committee design, is the key to this model's success. The effectiveness of a task force is firmly grounded in the group dynamics concept, which refers to a system of small-group behaviors based on interactions fostered through the relationships of members and leaders in connection with the complexities of the task involved. Therefore, the outcome of a successful task force assignment is greater than the product it produces; it also has the positive and much desired outcome of promoting 
Table 3. Hersey-Blanchard situational leadership theory: leadership styles

Behavior Type

Description

S1: Telling

S2: Selling

Leaders tell their people exactly what to do and how to do it.

S3: Participating

"sell" their message to get their team on board.

S3: Participating

Leaders focus more on the relationship and less on direction. The leader works with the team and shares decision making responsibilities.

S4: Delegating

Leaders pass off most of the responsibilities onto the follower or group. The leaders still monitor progress, but they are less involved in the decision.

Either Democratic, Autocratic, Collective-Participative, or Consensus

Table 4. Hersey-Blanchard situational leadership theory: maturity levels

Maturity Level

Description

M1 $\begin{aligned} & \text { These followers are at the bottom level of the scale. They lack the knowledge, skills, or confidence to } \\ & \text { work on their own, and they often need to be pushed. } \\ & \text { At this level, followers might be willing to work on the task, but they don't possess the skills to do it } \\ & \text { successfully. }\end{aligned}$
Followers are ready and willing to help with the task. They have more skills than the M2 group, but
they are still not confident in their abilities.
These followers are able to work on their own. They have high confidence and strong skills, and they
are committed to the task.

Table 5. Hersey-Blanchard situational leadership theory: maturity level/leadership style map

Maturity Level

Leadership Style

M1: Low maturity

S1: Telling/directing

M2: Medium maturity, limited skills

S2: Selling/coaching

M3: Medium maturity, higher skills but lacking confidence

S3: Participating/supporting

M4: High maturity

S4: Delegating

collaboration among individuals working together toward a common goal.

This collaborative task force follows the basic premise of group dynamics in the sense that the "whole becomes greater than the sum of its parts." This premise takes on greater importance and meaning when the group is coming to conclusions and making recommendations through the use of EBP methods. It is important to note that the task force teams do not make any decisions, but only make recommendations to the GDS AC. This highlights a point crucial to the success of task forces: the mechanisms set up to respond to task force recommendations. The more involvement task force members have in actually implementing their own recommendations, the more likely the recommendations are to be implemented..$^{22}$ This model is designed in such a manner that the task force leaders are part of the decision making body and are actively engaged in implementing their own recommendations.

The actual decision making process is left to the GDS AC based upon recommendations made by the specific task force leaders. The decision making effectiveness of a group is the result of many independent factors, but three main conditions have been identified that enable a group to make "high-quality" decisions. ${ }^{23}$ Those conditions are as follows: 1 ) exertion of sufficient effort to accomplish the task at an acceptable level of performance; 2) possession of adequate knowledge and skill relevant to the task at hand; and 3) utilization of task performance strategies that are appropriate to the work and to the setting in which it is being performed.

The GDS AC was designed to address each of these parameters in an effort to make high-quality decisions. The work ethic of the key departmental 
faculty members selected to serve on the GDS AC ensured that not only an appropriate effort would be put forth, but that there was no question as to their ability to accomplish the task at hand. An additional motivator was that they had a vested interest in the outcome of their task force's recommendation since they would be faced with implementing the recommendation should it be approved. These key departmental leaders were all chosen to lead task force teams due to their specific area of expertise and knowledge, so they were ideally suited to lead others in the investigation. The strategies employed mirror the highly successful EBP methods that work so well in a variety of professions, are ideally suited to curricular questions, and are a desired decision making tool.

Although there are low-quality decisions as well as high-quality decisions, a high-quality decision should come with a form of a guarantee. This is not a guarantee of a certain outcome, but a guarantee that the process used to arrive at the decision was an acceptable one. Acting in the comprehensive role of Manager requires devising or using a mechanism that is not only appropriate but also well regarded by the faculty through its rigor and thoroughness. The outlined task force model used in conjunction with EBDM techniques functions as a management tool to help achieve that goal and should ultimately lead to a higher quality decision.

The original rationale for this endeavor was the development of a strategy to educate, engage, and involve faculty members in EBP, but the design of this model also acts as a strategic faculty development tool. Acting in the comprehensive role of Faculty Developer requires supportive behaviors that increase faculty performance. One such supportive behavior that can be used to foster faculty productivity is modeling, and one of the most successful modeling techniques is to join faculty members in an interdisciplinary group collaborating on a project. Such an approach to teaching, scholarship, and service can help individuals break out of their own personal paradigms. ${ }^{17}$ Those selected as task force team members receive a first-hand, up-close experience in the fundamental methods of conducting EBD while working on a task that has the potential to change the curriculum. While they are engaged and focused on their specific assigned task, they are consciously or unconsciously learning about the benefits of EBD and becoming more conversant in its principles.
In addition to the three comprehensive roles discussed, a department chair, when acting in the comprehensive role of Scholar, must maintain his or her academic identity by continuing to teach. Whether this teaching occurs at the predoctoral level or by helping to educate colleagues, the discovery, enhancement, and transference of knowledge remain the essence of scholarly activity.

\section{Conclusions}

The creation of the Marquette University School of Dentistry's Department of General Dental Sciences Advisory Council introduced evidencebased decision making to the departmental faculty in an interdisciplinary workgroup environment that has fostered collaboration between colleagues. Although it is beyond the scope of this article to provide objective outcomes, early data suggest that this model has the potential to accelerate the decision making process, increase faculty consensus and acceptance of curricular changes, and calibrate the faculty by allowing them to participate throughout the process while learning or supplementing their knowledge of the fundamentals of evidence-based practice. As more measurable outcomes are generated, opportunities exist for a longitudinal assessment of the data to further analyze the model's success. Outcomes data being collected include, but are not limited to, the number of faculty ideas or suggestions for curricular change, the number of task force recommendations, the level of participation by full- and part-time faculty members, and the time frame required to complete a task, as well as a survey of faculty perceptions about the process. With the introduction of this model's design at our institution, members of the faculty have been able to witness that decisions related to changes in the department's curriculum are not made in an arbitrary manner or based upon personal biases, but rather on a systematic, evidence-based method of decision making that includes the voices of a broad cross-section of faculty members within the School of Dentistry.

\section{Acknowledgments}

The author would like to thank each of the nine original members of the Department of General Dental Sciences Advisory Council for their individual and collective efforts, expertise, and wisdom: David W. Berzins, Ph.D., Lisa J. Koenig, B.Ch.D., D.D.S., 
M.S., Toni M. Roucka, D.D.S., M.A., Harshit Aggarwal, B.D.S., M.S.D., Seok Hwan Cho, D.D.S., M.S., M.S., C.D.T., Soni Prasad, B.D.S., M.S., Conrad A. Nenn, D.D.S., Michael E. Grady, D.D.S., and Thomas J. Smithy, D.D.S.

\section{REFERENCES}

1. Stewart AF, Ferriero DM, Josephson SA. Fighting decision fatigue. Ann Neurol 2012;71(1):A5-A15.

2. Sinek S. Start with why: how great leaders inspire everyone to take action. New York: Penguin, 2009.

3. Ismail AI, Bader JD, ADA Council on Scientific Affairs and Division of Science. Evidence-based dentistry in clinical practice. J Am Dent Assoc 2004;135(1):78-83.

4. Das TK, Teng BS. Cognitive biases and strategic decision processes: an integrative perspective. J Manage Stud 1999;36(6):757-78.

5. Baumeister RF, Tierney J. Willpower: rediscovering the greatest human strength. New York: Penguin Books, 2011.

6. Leaming DR. Academic leadership: a practical guide to chairing the department. $2^{\text {nd }}$ ed. Bolton, MA: Anker Publishing Company, 2007.

7. Val MPD, Fuentes CM. Resistance to change: a literature review and empirical study. Manage Decis 2003;41(2):148-55.

8. Erwin DG, Garman AN. Resistance to organizational change: linking research and practice. Leadership Organization Dev J 2010;31(1):39-56.

9. Haden NK, Hendricson WD, Kassebaum DK, et al. Curriculum change in dental education, 2003-09. J Dent Educ 2010;74(5):539-57.

10. Sackett DL, Rosenberg WM, Gray JA, et al. Evidencebased medicine: what it is and what it isn't. BMJ 1996;312(7023):71-2.

11. Rugh JD, Hendricson WD, Hatch JP, Glass BJ. The San Antonio CATs initiative. J Am Coll Dent 2010;77(2): 16-21.
12. Rugh JD, Sever N, Glass BJ, Matteson SR. Transferring evidence-based information from dental school to practitioners: a pilot "academic detailing" program involving dental students. J Dent Educ 2011;75(10):1316-22.

13. Forrest JL, Miller SA, Overman PR, Newman MG. Evidence-based decision making. Philadelphia: Lippincott Williams \& Wilkins, 2008.

14. Ericsson KA, Smith J. Toward a general theory of expertise: prospects and limits. New York: Cambridge University Press, 1991.

15. Bertolami CN. Creating the dental school faculty of the future: a guide for the perplexed. J Dent Educ 2007;71(10):1267-80.

16. Creswell J, Wheeler D, Seagren A, Egly N. The academic chairperson's handbook. $2^{\text {nd }}$ ed. San Francisco: JosseyBass, 2008

17. Gmelch WH, Miskin VD. Chairing an academic department. $2^{\text {nd }}$ ed. Madison: Atwood Publishing, 2004.

18. Bolman LG, Deal TE. Reframing organizations: artistry, choice, and leadership. $3^{\text {rd }}$ ed. San Francisco: Jossey-Bass, 2003.

19. Hersey PH, Blanchard KH, Johnson DE. Management of organizational behavior. $10^{\text {th }}$ ed. Boston: Pearson Prentice Hall, 2008.

20. Crain G. Managing change in dental education: is there a method to the madness? J Dent Educ 2008;72(10): 1100-13.

21. Grigsby R. Task force, team: what's the difference? why does it matter? Acad Phys Scientist 2008;1:4-5.

22. Katzenbach JR, Smith DK. The wisdom of teams: creating the high-performance organization. $3^{\text {rd }}$ ed. New York: Harper Business, 2003.

23. Frey LR, Gouran D, Poole S. The handbook of group communication theory and research. London: Sage Publications, 1999. 